Island Studies Journal, Vol. 9, No. 2, 2014, pp. 363 - 366

\title{
A note on the significance of geographic location in island studies
}

\author{
Jerome L. McElroy \\ Saint Mary's College \\ Notre Dame, IN \\ USA \\ jmcelroy@saintmarys.edu \\ and \\ Holly Lucas \\ Valparaiso University Law \\ Buchanan, MI \\ USA \\ hdmlucas@gmail.com
}

\begin{abstract}
This exploratory study suggests that over half of island welfare can be explained primarily by geographic proximity to world markets and affiliated political status. This result is drawn from a provisional test of geographical location on the economic performance of 34 small island jurisdictions and Gibraltar.
\end{abstract}

Keywords: geography, great circle distance, islands, regression, standard of living

(C) 2014 - Institute of Island Studies, University of Prince Edward Island, Canada.

\section{Introduction}

A number of island scholars have recently emphasized the important influence of geography in determining insular standards of living. For example, according to Armstrong et al. (1998, p. 653), "the region in which a micro-state is located plays an important role in influencing GDP/GNP per capita: micro-states in poor regions also tend to be poor." In a follow-up study of a very large number of small states in general and Pacific islands in particular, Armstrong and Read (2006, p. 89) found that remoteness from global markets in North America, Europe and Asia is the "characteristic that appears to be the most serious handicap for the small Pacific states and dependent territories." In the same study, they also argue that Pacific states tend to be hampered because they are more mountainous and archipelagic than other small islands.

Several other authors have attempted to explain differences in economic performance especially among Caribbean and Pacific small islands in terms of geographic contrasts. For example, McElroy and Medek (2012) argue that the greater remoteness of Pacific islands from world markets places that island region at a relative commercial disadvantage while conversely the greater proximity of the Caribbean archipelago to North American and European markets places that region at a competitive advantage. Similarly, Watsa (2009), using population and income weighted distance measures, concludes that the average Pacific island is significantly more remote than the average Caribbean island. More specifically, Gibson and Nero (2008) suggest the barrier of distance explains why the Pacific is less open to trade than the Caribbean and less accessible to the visitor industry and the postwar insular growth engine of international tourism development. 


\section{J. L. McElroy \& H. Lucas}

In a similar vein, Shareef and others (2008) indirectly argue that favorable geographycum-tourism explains part of the stronger performance of Caribbean and Mediterranean over more relatively distant Pacific and Indian Ocean islands. Along the same lines, McElroy and Morris (2002) find that African islands, partly because of their market remoteness, are less advanced than small islands across the rest of the world. In addition, Thornburn (2007) reports that Pacific islands in particular are more fragmented and distant from one another than other island regions and thus less susceptible to commercial development that relies on transport economies.

\section{Scope and Method}

Since the handicap of distance is a recurring theme in the island economy literature, this note is a provisional first attempt to determine the relative contribution of geography vis-à-vis other macro influences toward explaining insular living standards. To test the impact of geographical location on island welfare, Great Circle Distance (GCD) was employed as a measure of remoteness/proximity since it was successfully used by Armstrong and Read (2006). GCD is the distance from each island's capital city to the nearest of three major tourist origin markets: in Brussels (Belgium/Europe), Washington DC and/or Los Angeles CA (United States), and Tokyo (Japan/Asia). The dependent variable, island standard of living, was measured as per capita GDP (PPP).

Four other independent determinants were examined that have appeared significant in island research. First, political status - measured simply dichotomously as one (1.0) for sovereign and zero (0.0) for affiliated islands - was used since Baldacchino's (2006) PROFIT model argues such subnational island jurisdictions (SNIJs) parlay their jurisdictional resources to wrest benefits from their metropolitan patrons and establish profitable niches (free-trade zones, tax havens, offshore banking etc.) in the global economy. Second, services as a percent of GDP was used as a proxy measure to capture the important contribution of tourist development to small tropical island economies or so-called SITEs (McElroy, 2006). Third, the labour force participation rate (LFPR) was employed to indirectly measure the extent of economic integration and modernization. It was believed that greater labour force participation was associated with greater market employment outside the home, a more vibrant private sector, and further development beyond subsistence. Finally, three measures of social/health advancement were alternatively employed - life expectancy, adult literacy, and infant mortality - on the assumption that improved labour force quality would positively affect island welfare. All data except GCD were taken from The World Factbook (2013).

To operationalize a series of regression experiments, 35 mainly small islands were selected that met the under three million population size criterion for smallness, and for which a full data set is available. In addition, a concerted attempt was undertaken to ensure that all oceanic regions were represented. Thirteen dependent and twenty-two independent islands were selected. Ten are located in the Caribbean: Aruba, Barbados, British Virgin Islands, Dominica, Grenada, St. Kitts and Nevis, St. Lucia, Trinidad and Tobago, Turks and Caicos, and the U.S. Virgin Islands. Another ten are located in the Pacific: Cook Islands, Guam, Fiji, Marshall Islands, Nauru, Palau, Solomon Islands, Tuvalu, Tonga and Vanuatu. There are seven in the Atlantic: Cape Verde, Faroe Islands, Guernsey, Isle of Man, Jersey, Saint Helena and Sao Tome and Principe. Three are located in the Mediterranean: Cyprus, Malta and Gibraltar, the Spanish peninsular British dependency. Finally, five are located in the Indian Ocean: Comoros, Maldives, Mauritius, Mayotte and Seychelles. 
Based on the results of past studies (McElroy \& Parry, 2010; Armstrong \& Read, 2006), it was hypothesized that islands more proximate to world markets would have higher per capita income than their more remote counterparts. In addition, they would likewise tend to be more politically affiliated and exhibit greater tourism intensity, labour force participation and social/health advancement.

\section{Results}

In this provisional analysis, initially eight regression experiments were conducted employing various combinations of independent variables to uncover the major determinants of island standard of living as measured by per capita GDP. In every regression, Great Circle Distance (GCD) was a statistically significant determinant. A typical example is Equation 1 in Table 1. Accordingly, the combination of GCD, the labour force participation rate (LFPR), service activity as a proxy for tourism, political status (STATUS) and life expectancy (LE) "explain" close to 60 percent of the variation in per capita income. However, only GCD is statistically significant at the 0.01 level, and the sign of the coefficient is negative indicating as hypothesized that remoteness is detrimental to per capita island welfare. In fact GCD alone "explains" over 50 percent of per capita GDP variation.

On the other hand, Equation 2 is the only regression experiment where any variable other than GCD demonstrated any significant influence on per capita GDP. In this case, again GCD is highly statistically significant at the 0.01 level and negative as hypothesized while the LFPR and STATUS are significant at the 0.05 percent level. The LFPR is positive indicating greater insular affluence is associated with a greater degree of economic modernization and development. In addition, the STATUS variable is negative, suggesting the advantages of political affiliation as Baldacchino (2006) has long argued. These three variables "explain" 56 percent of the variation in island per capita GDP. Analysis of variance indicates that GCD alone is responsible for 28 percent of the total variation and political status contributes 26 percent while LFPR adds only 5 percent.

\section{Conclusion}

This note reviews recent literature emphasizing the significant influence of distance as a determinant of island welfare. It conducted a provisional test of geographical location on the economic performance of 34 small islands less than three million in population and Gibraltar. It sought to measure the relative influence of distance on island welfare against other influences such as political status, tourism as measured by the service share of GDP, labour force participation as a proxy for modernity and various indicators of health and social advancement. Great Circle Distance (GCD) was employed to measure geographical distance.

In all the multivariate regression tests conducted, GCD was the only independent variable that was always highly statistically significant (at the 0.01 level or better). In the bestfit model, GCD, dependent political status and labour force participation accounted for 56 percent of the variation in island per capita GDP, and GCD accounted for half of that variation.

In brief, the study suggests that, for this sample of small islands, over half of island welfare can be explained primarily by geographic proximity to world markets and affiliated political status. It suggests future explorations of island economic performance include the role of distance. Ongoing research should attempt to replicate these findings with a larger sample of islands and alternative measures of the independent influences. 


\section{References}

Armstrong, H. W., de Kervenoael, R. J., Li., X., \& Read, R. (1998). A comparison of the economic performance of different micro-states, and between micro-states and larger countries. World Development, 26(4), 639-656.

Armstrong, H. W., \& Read, R. (2006). Comparing the economic performance of dependent territories and sovereign micro-states. Economic Development \& Cultural Change, 48(2), 285-306.

Baldacchino, G. (2006). Managing the hinterland beyond: ideal-type strategies of economic development for small island territories. Asia Pacific Viewpoint, 47(1), 45-60.

Central Intelligence Agency. (2013). The world factbook. Washington, DC. Retrieved from https://www.cia.gov/library/publications/the-world-factbook/index.html

Gibson, J., \& Nero, K. (2008). Why don't Pacific island countries' economies grow faster? In A. Bisby (Ed.) Pacific interactions (pp. 191-244). Wellington, NZ: Victoria University.

McElroy, J. L. (2006). Small island tourist economies across the life cycle. Asia Pacific Viewpoint 47(1), 61-77.

McElroy, J. L., \& Medek, K. J. (2012). Small island economies: Caribbean versus Pacific. Bank of Valletta Review, 46(1), 17-32.

McElroy, J. L., \& Morris, L. (2002). African island development experiences: a cluster of models. Bank of Valletta Review, 26, 38-57.

McElroy, J. L., \& Parry, C. E. (2010). The characteristics of small island tourist economies. Tourism and Hospitality Research, 10(4), 315-328.

Shareef, R., Hoti, S., \& McAleer, M. (2008). The economics of small island tourism: International demand and country risk analysis. Northampton, MA: Edward Elgar.

Thornburn D. (2007). The 'patch' and the 'backyard': Caribbean and Pacific small islands and their regional hegemons. Social and Economic Studies, 56(1-2), 240-260.

Watsa, K. (Ed.) (2009). Pacific Islands development in 3D: Reshaping economic geography. Washington, DC: The World Bank.

Table 1: Regression Results

\begin{tabular}{|llllllll|}
\hline Equation & Variable & Coefficient & T & P & R2(adj) & F & P \\
& GCD & -2.6264 & -3.12 & 0.004 & $58.2 \%$ & 10.48 & 0.000 \\
& LFPR & 218.9 & 1.54 & 0.134 & & & \\
& Services & -19.2 & -0.14 & 0.887 & & & \\
& STATUS & -4991 & -1.08 & 0.288 & & & \\
& LE & 808.9 & 1.59 & 0.123 & & & \\
& & & & & & & \\
& GCD & -3.0267 & -3.64 & 0.001 & $56.3 \%$ & 15.61 & 0.000 \\
& STATUS & -9088 & -2.20 & 0.036 & & & \\
& LFPR & 287.8 & 2.05 & 0.048 & & & \\
\hline
\end{tabular}

